\title{
Synoptic-scale circulation patterns during summer derived from tree rings in mid-latitude Asia
}

\author{
Andrea Seim ${ }^{1} \cdot$ Johannes A. Schultz $^{2}$ - Caroline Leland ${ }^{3}$ Nicole Davi ${ }^{3,4}$. \\ Oyunsanaa Byambasuren $^{5}$ Eryuan Liang ${ }^{6}$ Xiaochun Wang ${ }^{7}$. Christoph Beck ${ }^{8}$. \\ Hans W. Linderholm ${ }^{1} \cdot$ Neil Pederson ${ }^{3,9}$
}

Received: 7 March 2016 / Accepted: 24 October 2016 / Published online: 3 November 2016

(C) The Author(s) 2016. This article is published with open access at Springerlink.com

\begin{abstract}
Understanding past and recent climate and atmospheric circulation variability is vital for regions that are affected by climate extremes. In mid-latitude Asia, however, the synoptic climatology is complex and not yet fully understood. The aim of this study was to investigate dominant synoptic-scale circulation patterns during the summer season using a multi-species tree-ring width (TRW) network comprising 78 sites from mid-latitude Asia. For each TRW chronology, we calculated an atmospheric circulation tree-ring index (ACTI), based on $1000 \mathrm{hPa}$ geopotential height data, to directly link tree growth to 13 summertime weather types and their associated local climate conditions for the period 1871-1993. Using the ACTI, three groups of similarly responding tree-ring sites can be associated with distinct large-scale atmospheric circulation patterns: 1 . growth of drought sensitive trees is positively affected by a cyclone over northern Russia; 2 . temperature sensitive trees show positive associations to a cyclone over northwestern
\end{abstract}

Electronic supplementary material The online version of this article (doi:10.1007/s00382-016-3426-7) contains supplementary material, which is available to authorized users.

Andrea Seim

andrea.seim@gvc.gu.se

1 Regional Climate Group, Department of Earth Sciences, University of Gothenburg, Gothenburg, Sweden

2 Remote Sensing Research Group (RSRG), Department of Geography, University of Bonn, Bonn, Germany

3 Tree-ring Laboratory, Lamont-Doherty Earth Observatory, Palisades, NY, USA

4 Department of Environmental Science, William Paterson University, Wayne, NJ, USA

5 Regional Central Asia Fire Management Resource Center, National University of Mongolia, Ulaanbaatar, Mongolia
Russia and an anticyclone over Mongolia; 3. trees at two high elevation sites show positive relations to a zonal cyclone extending from mid-latitude Eurasia to the West Pacific. The identified synoptic-scale circulation patterns showed spatiotemporal variability in their intensity and position, causing temporally varying climate conditions in mid-latitude Asia. Our results highlight that for regions with less pronounced atmospheric action centers during summer such as the occurrence of large-scale cyclones and anticyclones, synoptic-scale circulation patterns can be extracted and linked to the Northern Hemisphere circulation system. Thus, we provide a new and solid envelope for climate studies covering the past to the future.

Keywords Atmospheric circulation tree-ring index . Mid-latitude Asia · Objective weather-type classification . Principal component analysis $\cdot$ Synoptic-scale circulation pattern $\cdot$ Tree rings

6 Key Laboratory of Tibetan Environment Changes and Land Surface Processes (TEL), Institute of Tibetan Plateau Research, Chinese Academy of Sciences, Beijing, China

7 Center for Ecological Research, Northeast Forestry University, Harbin, Heilongjiang, China

8 Institute of Geography, University of Augsburg, Augsburg, Germany

9 Present Address: Harvard Forest, Harvard University, Petersham, MA, USA 


\section{Introduction}

Understanding past and future climatic variations and their synoptic associations is essential for socioeconomic and environmental wellbeing in Asia. Drought-prone regions in mid-latitude Asia, including Mongolia and northern China, have experienced severe climate extremes during the last century, mainly related to precipitation (e.g. Liu et al. 2013; Pederson et al. 2014; Liang et al. 2016) that have contributed to significant societal hardships (e.g. Rao et al. 2015). As extreme hot events are likely to increase in intensity, duration and frequency in the future (IPCC 2013), and warming temperatures will potentially exacerbate droughts in this region (Pederson et al. 2014; Davi et al. 2015; Liang et al. 2016), it is important to understand the natural range of historical climate variability. Moreover, a comprehensive picture of dominant atmospheric circulation patterns that influence local and regional climate conditions in mid-latitude Asia is vital for understanding how regional climate might change in the future.

Mid-latitude (arid and semi-arid) Asia experiences an extreme continental climate with cold winters and hot but short summers. Weather conditions during winter are closely linked to the Siberian High, which is centered over Lake Baikal, causing strong northerly winds and extreme low temperatures in Eurasia (Perry 1971; Sahsamanoglou et al. 1991; Böhner 2006). However, during summer, when the Siberian High dissipates, air masses of mid-to-high latitude continental and maritime origin affect the climate in mid-latitude Asia. This leads to two distinct climate regimes: (1) an arid inland Asia climate (including central Asia, arid northwest China and the northern Tibetan Plateau) that is predominantly influenced by the mid-latitude westerlies and (2) a humid south-eastern Asia climate controlled by the monsoon circulation (Chen et al. 2008; Böhner 2006) (Fig. 1a). Despite these two distinct climatic

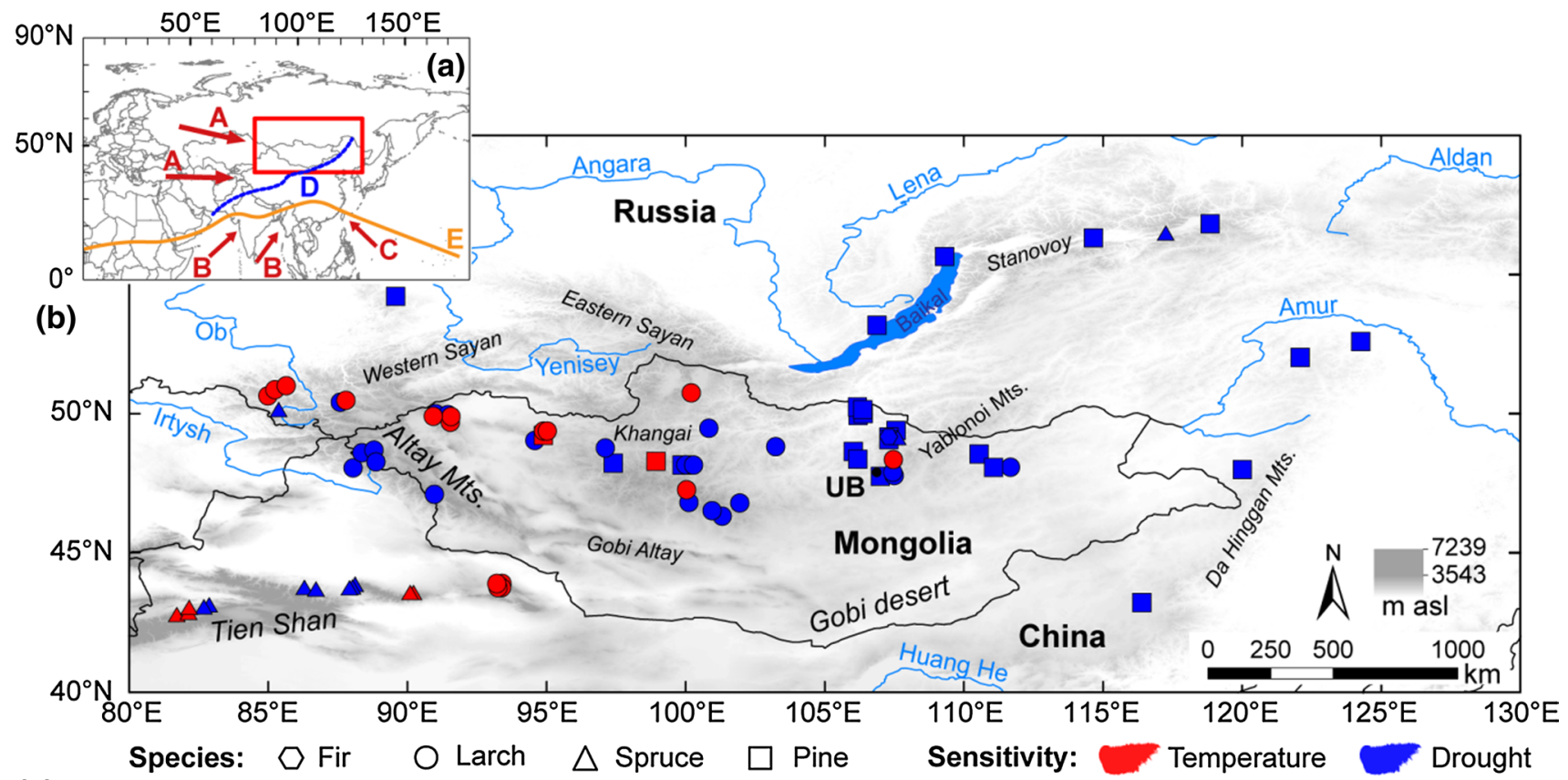

(c) 3.0

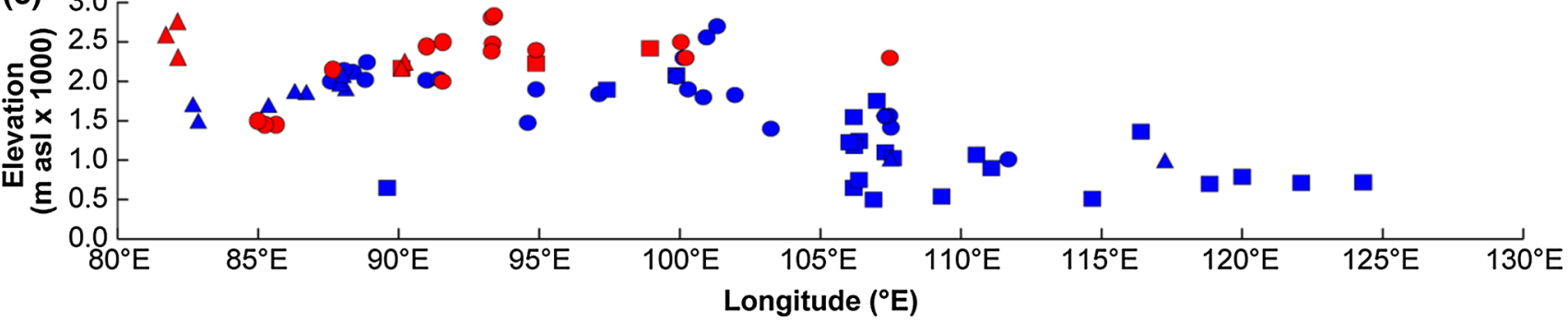

Fig. 1 a Location of the study region (red square) and the main circulation systems during summer [westerlies $(A)$, Indian summer monsoon $(B)$, East Asian summer monsoon $(C)$, modern Asian summer monsoon limit $[D$; after Chen et al. (2008)] and the Intertropical Con- vergence Zone ( $E$; for July)] and (b) the geographical position of the individual tree-ring width (TRW) site chronologies, shown regarding their climatic response (blue drought; red temperature), species, and (c) altitude. UB stands for the Mongolian capital Ulan Bator 
regimes, elements driving climate of this region are complex. Evidence suggests that summer climate in our study area is influenced by the North Atlantic Oscillation (NAO) (Li et al. 2008; Folland et al. 2009; Linderholm et al. 2011; Zhu et al. 2011; Sun and Wang 2012), the Atlantic Multidecadal Oscillation (Wang et al. 2011), the Arctic Oscillation (Gong and Ho 2003), the Pacific Decadal Oscillation (Wang et al. 2000; Wang 2006), the Asian summer monsoon system (Ding 2004) which is associated with the El Niño Southern Oscillation (Zhang et al. 1999; Lu 2005) and the Intertropical Convergence Zone, and their interactions on different spatial and temporal scales. This multitude of atmospheric circulation patterns so far associated with climate in mid-latitude Asia highlights the need to refine the synoptic climatology, i.e. the relationship between local/ regional climate and atmospheric circulation (Barry and Carleton 2001) in this region.

To study past climate variability and impacts of current climate change, tree rings are a widely employed terrestrial climate proxy. In the extra-tropics, trees develop annual rings due to the seasonal periodicity of growth processes (Vaganov et al. 2006) and the radial increments are strongly influenced by weather conditions during the growing season of previous and current years (Fritts 1976). By using this relationship and the development of large tree-ring networks, we can extend our understanding of spatiotemporal climate variability further in the past than with instrumental data. In mid-latitude Asia, most meteorological stations started operating in 1950. The strong tree growth-climate relationships in mid-latitude Asia are shown by the high quantity of existing reconstructions of hydroclimate including drought (e.g. Pederson et al. 2001; Davi et al. 2006, 2009; Cook et al. 2010; Fang et al. 2010, 2012; Bao et al. 2015) and temperature (e.g. Jacoby et al. 1996; D'Arrigo et al. 2000, 2001; Chen et al. 2013; Davi et al. 2015). In some cases, the spectral properties of the reconstructions were investigated to identify primary climate drivers in the region. In general, the mid-latitudes are a region where a high atmospheric variability exists and where a great variety of large-scale teleconnection patterns are observed that have an effect on the summer climate, and thus tree growth, in this continental region. In this regard, new approaches are needed to disentangle the spatiotemporal interaction of dominating circulation patterns that define local and regional climates (Barry and Carleton 2001).

To advance the understanding of drivers of climate in this region, we apply a new method to study the influence of weather types (i.e. characteristic configurations of synoptic-scale pressure systems) on tree growth in mid-latitude Asia. This involves the calculation of an atmospheric circulation tree-ring index (ACTI), which has been successfully applied on a European tree-ring network (Schultz and Neuwirth 2012; Schultz et al. 2015). It has been demonstrated that the NAO caused species- and site-specific climate response patterns. For instance, growth conditions for spruce and oak in Central Europe was enhanced during the positive NAO phase, when increased zonal wind flow caused warmer and wetter spring climate conditions (Schultz and Neuwirth 2012).

This study aimed at (1) testing the new ACTI method using tree rings from mid-latitude Asia and (2) extracting and identifying dominant synoptic-scale circulation patterns during summer that control local and regional climate and hence, influence tree growth. We used a tree-ring width (TRW) network consisting of 78 sites and an objective classification of 13 summertime weather types derived from $1000 \mathrm{hPa}$ geopotential height data. We calculated the ACTI, i.e. the extracted weather-type signal, for each TRW site chronology. We identified three major atmospheric circulation patterns, which were investigated regarding their effect on tree growth and their spatiotemporal characteristics.

\section{Data and methods}

\subsection{Tree-ring network}

We compiled 78 site chronologies comprising 2928 individual TRW measurements in the $40-60^{\circ} \mathrm{N}$ and $80-130^{\circ} \mathrm{E}$ region covering northern China $(\mathrm{CN})$, all of Mongolia (MN) and southern Russia (RU) and the common period 1871-1993 (Figs. 1, 2a and Tab. S1). The majority of the data (60 TRW chronologies) in the network were publically available from the International Tree-Ring Data Bank (http://www.ncdc.noaa.gov/paleo/treering.html), and data from additional 18 sites were provided by the authors. Our TRW network includes Siberian fir (Abies sibirica Ledeb.) and different native sub-species of the genera larch (Larix spp.: L. gmelinii (Rupr.) Rupr., L. sibirica Ledeb.), spruce (Picea spp.: P. obovata Ledeb., P. shrenkiana Fisch. and Meyer, P. tienschanica Rupr.) and pine (Pinus spp.: P. sibirica Du Tour, P. sylvestris L., P. tabulaeformis Carr.). The sampling sites varied in elevation from 500 to $2840 \mathrm{~m}$ above sea level (m asl) (Fig. 1b, c). All TRW data underwent a visual crossdating, followed by statistical verification using the software COFECHA (Holmes 1983). Only sites with an interseries correlation (Rbar) higher or equal to 0.45 were retained to maintain a high common signal within a stand.

We removed climate-unrelated but biologically induced trends due to increasing age and size of the trees, so-called age trends, by using a cubic smoothing spline with $50 \%$ frequency-response cut-off at 150 years (150 years SPL) in the program ARSTAN (Cook and Krusic 2005). This standardization technique retains year-to-year high-frequency variability as well as multi-decadal trends (i.e. $50 \%$ of the 


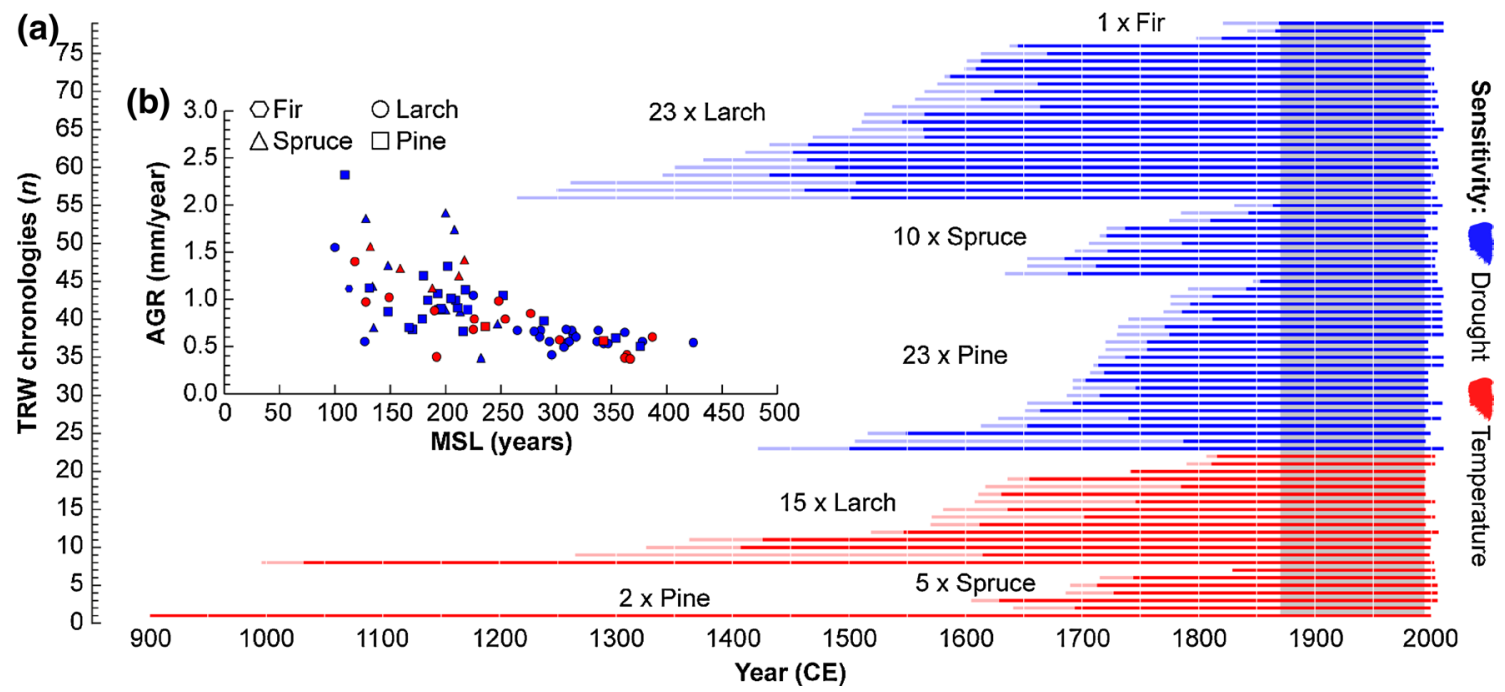

Fig. 2 a Temporal coverage of the multi-species TRW network before (shaded color) and after truncation at a minimum of 10 series (full color) and the (b) average growth rates (AGR) plotted against the site chronologies' mean segment length (MSL) with respect to the climate response of each site (see legend). The common period 18711993 is highlighted in grey variance remains preserved at 150 years). Prior to detrending, biases associated with heteroscedastic variances were reduced by applying an adaptive power transformation (Cook and Peters 1997) and TRW indices were calculated as residuals. Additionally, due to uneven sample replication and thus, changes in variance over time, we adjusted the variance using the Rbar weighted stabilization method (Cook 1985). The final stabilized and detrended TRW indices were used and chronologies were subsequently generated as bi-weight robust means.

Each TRW site chronology was truncated at a minimum of 10 series per year (Fig. 2a) to reduce biases caused by a low sample replication. The statistically robust period was evaluated using the expressed population signal (Wigley et al. 1984), a measure for the common signal strength of a chronology.

\subsection{Monthly reanalysis data}

We used the NOAA-CIRES twentieth century reanalysis data (Compo et al. 2011) covering the period 1871-2010. First, an objective weather-type classification was generated by applying the COST733 classification software (Philipp et al. 2010, 2014) to sub-daily $(0,6,12,18$, UTC) $2^{\circ}$ by $2^{\circ}$ gridded $1000 \mathrm{hPa}$ geopotential height data over its full time span. It should be noted that the $500 \mathrm{hPa}$ geopotential height dataset was also utilized, however, the resulting growth-weather type responses were similar but overall less pronounced (not shown). To compute the weather-type classification, the distributed k-means approach (Enke and Spekat 1997), which is based on nonhierarchical k-means clustering, was applied (e.g. Hartigan
1975). Distributed k-means uses most dissimilar cases (geopotential height fields) to identify the starting partition (Philipp et al. 2014; Enke and Spekat 1997) for the subsequent iterative reassignment of cases to classes. This procedure persists until no further reduction of the withincluster variances can be obtained. As previous studies have shown, the distributed k-means approach has the ability to resolve surface climate variations (Beck and Philipp 2010). The weather types were computed for the spatial domain $35-65^{\circ} \mathrm{N}$ and $75-135^{\circ} \mathrm{E}$, slightly larger than for the treering network, so that all relevant circulation features could be captured.

Since annual TRW variability in this region is strongly influenced by summer weather conditions, we focused on tree-growth response and prevailing synoptic conditions during the June-August season. Thus, sub-daily weather type data were combined to summer averages. We used a classification with 27 weather types and, from those, 13 prevail during the summer season in our study area. The type composites (centroids) of the individual weather types are shown in Fig. 3 (and Fig. S3). In comparison, the ensemble mean of the geopotential height anomalies at $1000 \mathrm{hPa}$ and $500 \mathrm{hPa}$ of the twentieth century reanalysis dataset for all summers between 1871 and 1993 is provided in Figure S1.

\subsection{ACTI calculation}

Based on literature and an a priori check of the growthclimate response of each detrended TRW site chronology, i.e. via simple Pearson correlation statistics between each site chronologies and climate parameters, the network 


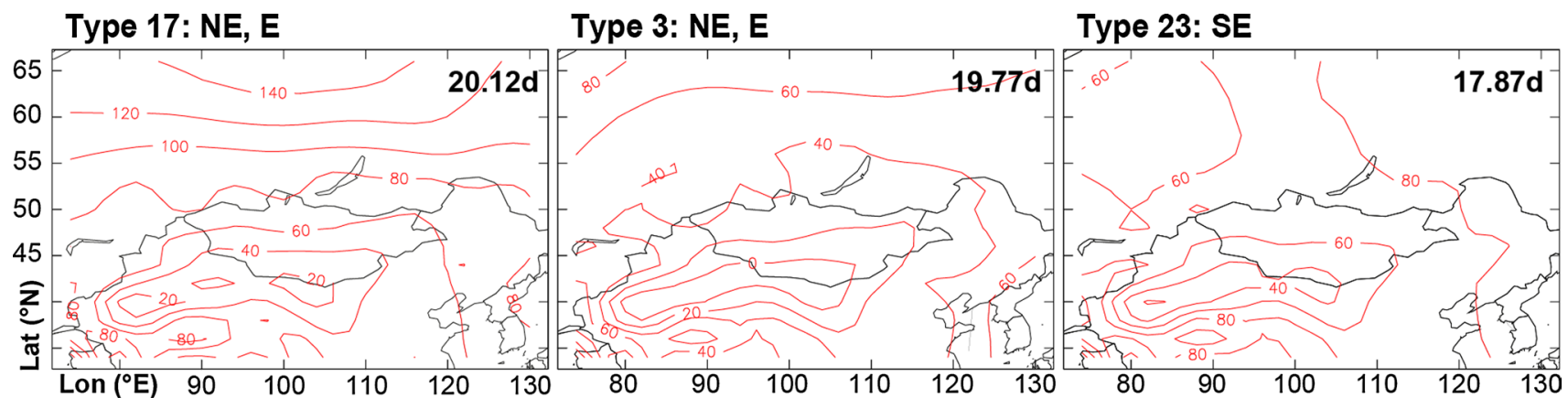

Type 21: N, NE

Type 8: NE, E

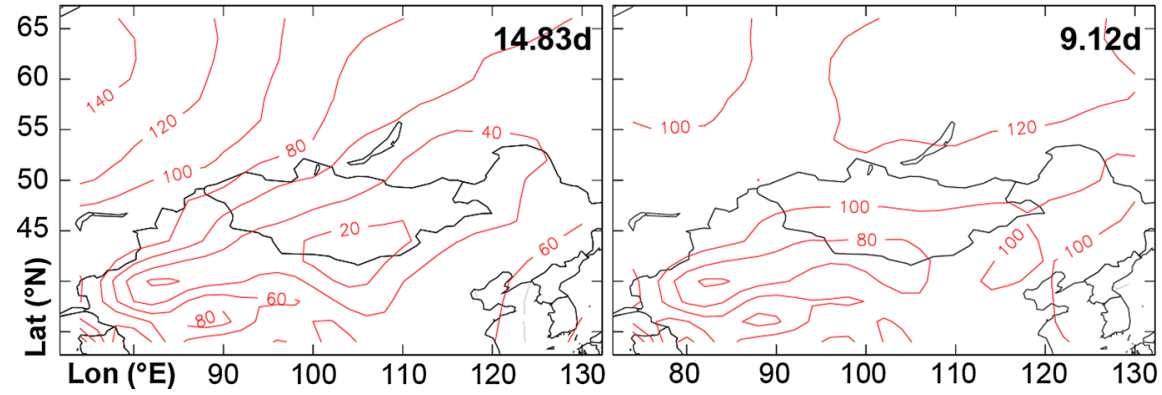

Type 11: N, NE

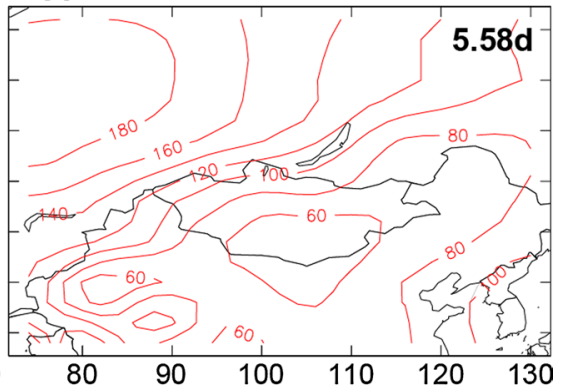

Fig. 3 Synoptic maps of the six most frequent weather types showing geopotential heights $(\mathrm{m})$ of the $1000 \mathrm{hPa}$ pressure level during June-August for the period 1871-1993. Average number of days

(d) that each weather type occurred in summer over the investigated period and prevailing wind direction is provided

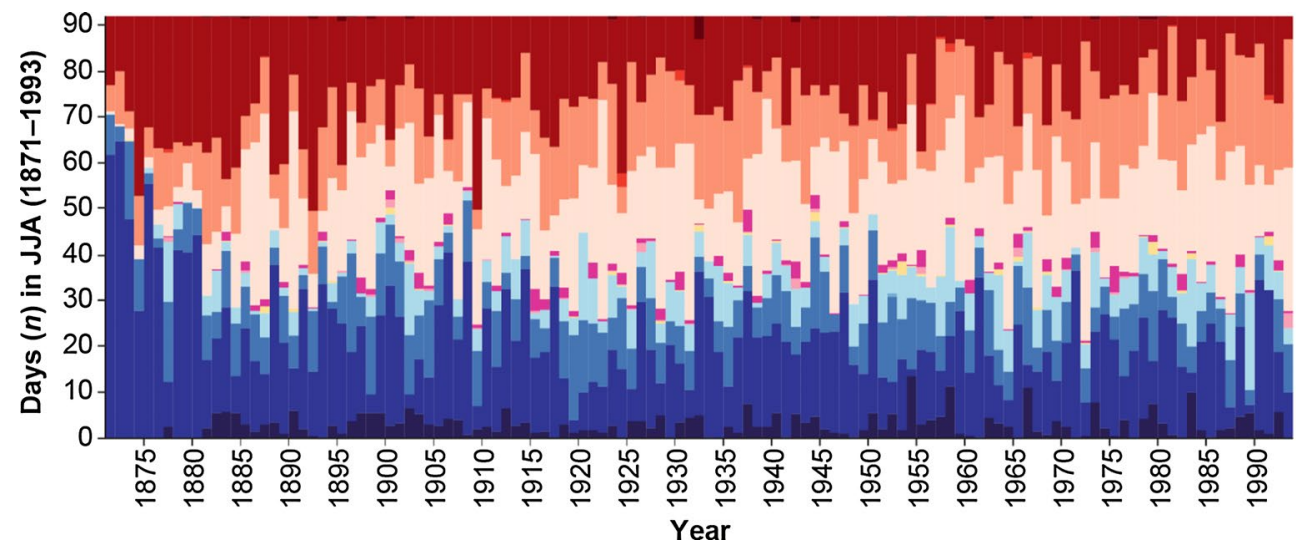

\section{Weather type \\ $\square 1 \square 21$ \\ $\because 3 \quad 22$ \\ $\square 8 \square 23$ \\ $\square 10 \square 26$ \\ 11 \\ 12 \\ 15 \\ 16 \\ 17}

Fig. 4 Number of days for each weather type during summer (June-August) for the period 1871-1993. Bold numbers in the legend indicate the six most frequent types

encompassed 56 summer drought and 22 summer temperature sensitive chronologies (Fig. 1). It should be noted that sites from different geographical locations can react differently or even inversely to the same weather type.

Following Schultz and Neuwirth (2012), an ACTI time series was computed for each TRW chronology for the common 1871-1993 period. ACTI links weathertype data with proxy data such as TRW chronologies. In our study, the values of the ACTI time series are defined as June-August sums of the weighted weather-type frequencies during the period 1871-1993 (Fig. 4), which is expressed as:

$\operatorname{ACTI}_{y}=\sum_{j=1}^{w}\left(h_{y j} \times g_{j}\right)$.

Here, every weather type $j=1, \cdots, w$ (here $w=13$ ), its frequency $\left(h_{y j}\right)$ and its weight $\left(g_{j}\right)$ (i.e. influence of each 
Table 1 Weight $\left(g_{j}\right)$ in percentage (\%) of each summertime weather type (WT, see Fig. 4) on the ACTI records extracted from the site chronologies for the period 1901-1993

\begin{tabular}{|c|c|c|c|c|c|c|c|c|c|c|c|c|c|}
\hline Site & WT1 & WT3 & WT8 & WT10 & WT11 & WT12 & WT15 & WT16 & WT17 & WT 21 & WT22 & WT23 & WT 26 \\
\hline chin 013 & 1.7 & 39.1 & 6.5 & 0.4 & 0.8 & 0.9 & 1.7 & 2.9 & 6.6 & 29.1 & 2.2 & 8.2 & 0.0 \\
\hline chin 014 & 0.5 & 19.8 & 4.9 & 0.4 & 8.9 & 0.6 & 5.8 & 1.1 & 5.5 & 37.8 & 2.0 & 12.6 & 0.2 \\
\hline chin 015 & 1.1 & 36.4 & 6.2 & 0.3 & 2.9 & 1.1 & 3.4 & 2.1 & 7.4 & 25.6 & 1.9 & 11.3 & 0.3 \\
\hline chin 033 & 0.5 & 23.7 & 1.9 & 0.4 & 14.2 & 1.0 & 5.3 & 0.5 & 3.4 & 38.9 & 3.3 & 6.8 & 0.1 \\
\hline chin 034 & 0.5 & 17.3 & 3.1 & 0.5 & 9.7 & 0.7 & 4.4 & 0.7 & 4.6 & 42.2 & 2.1 & 14.1 & 0.1 \\
\hline Taksimo & 3.1 & 36.8 & 5.9 & 0.6 & 3.6 & 0.2 & 9.6 & 0.9 & 12.0 & 19.0 & 2.8 & 5.3 & 0.3 \\
\hline mong013 & 0.7 & 39.5 & 2.8 & 0.3 & 3.6 & 0.0 & 7.0 & 0.4 & 3.9 & 9.1 & 0.2 & 32.3 & 0.4 \\
\hline mong022 & 2.1 & 22.7 & 5.1 & 0.4 & 3.9 & 0.8 & 5.2 & 0.8 & 0.1 & 9.4 & 0.4 & 48.7 & 0.5 \\
\hline mong023 & 1.1 & 25.4 & 2.9 & 0.1 & 3.7 & 0.2 & 8.1 & 0.7 & 3.2 & 10.2 & 0.9 & 43.1 & 0.4 \\
\hline mong027 & 0.2 & 28.8 & 2.4 & 0.8 & 1.5 & 0.5 & 4.8 & 0.2 & 3.7 & 39.3 & 0.7 & 16.7 & 0.4 \\
\hline mong028 & 2.0 & 19.2 & 6.0 & 0.4 & 5.1 & 0.6 & 4.7 & 0.9 & 0.1 & 8.6 & 0.5 & 51.5 & 0.5 \\
\hline BG & 1.3 & 14.3 & 5.3 & 0.4 & 7.1 & 0.3 & 0.2 & 0.4 & 2.6 & 14.0 & 3.8 & 49.8 & 0.4 \\
\hline DKN & 2.3 & 42.4 & 10.1 & 0.1 & 16.4 & 1.1 & 3.5 & 1.5 & 1.1 & 3.9 & 4.4 & 13.0 & 0.3 \\
\hline NTD & 2.2 & 0.5 & 0.2 & 0.7 & 3.0 & 0.7 & 1.5 & 0.8 & 3.4 & 20.6 & 1.7 & 64.8 & 0.0 \\
\hline SMN & 2.4 & 42.7 & 8.1 & 0.4 & 9.3 & 0.4 & 0.2 & 1.3 & 2.4 & 2.7 & 3.3 & 26.6 & 0.4 \\
\hline TNC & 0.8 & 38.7 & 7.1 & 0.1 & 7.2 & 0.5 & 1.7 & 0.2 & 1.6 & 14.2 & 3.6 & 24.3 & 0.1 \\
\hline russ167 & 0.5 & 46.6 & 7.1 & 0.0 & 6.4 & 0.8 & 6.4 & 0.2 & 4.4 & 21.7 & 2.5 & 3.3 & 0.1 \\
\hline russ172 & 0.2 & 12.1 & 1.4 & 0.8 & 7.7 & 0.2 & 1.0 & 2.2 & 2.8 & 40.5 & 5.0 & 26.1 & 0.1 \\
\hline KN4-LASI & 0.1 & 1.1 & 6.5 & 2.8 & 4.2 & 0.1 & 3.9 & 0.8 & 2.6 & 49.7 & 2.2 & 25.8 & 0.2 \\
\hline chin008 & 0.4 & 10.2 & 0.5 & 1.7 & 7.6 & 0.6 & 5.0 & 1.3 & 3.5 & 29.4 & 4.6 & 35.1 & 0.1 \\
\hline chin009 & 0.4 & 13.0 & 1.3 & 0.6 & 2.6 & 1.2 & 1.0 & 0.1 & 0.5 & 28.2 & 4.3 & 46.5 & 0.4 \\
\hline chin 010 & 0.4 & 8.7 & 0.1 & 1.7 & 5.9 & 0.5 & 3.9 & 0.8 & 3.3 & 31.1 & 4.5 & 39.1 & 0.1 \\
\hline chin 036 & 0.4 & 17.4 & 5.6 & 0.0 & 3.9 & 1.2 & 3.7 & 0.1 & 3.3 & 35.1 & 4.3 & 24.9 & 0.1 \\
\hline mong021 & 1.5 & 20.3 & 3.2 & 0.1 & 4.5 & 0.2 & 4.4 & 1.6 & 3.1 & 11.4 & 1.9 & 47.5 & 0.2 \\
\hline russ140 & 0.9 & 26.2 & 3.3 & 0.4 & 1.6 & 0.5 & 5.8 & 1.2 & 1.8 & 18.7 & 0.8 & 38.5 & 0.4 \\
\hline
\end{tabular}

Numbers in bold highlight the influence of each weather type on ACTI by more than $25 \%$ while blue (red) colors represent weather types with negative (positive) influences on tree growth

weather type on tree growth) is used to calculate $\mathrm{ACTI}_{y}$ with $y=1, \ldots, t$ (here $t=123,1871-1993$ ) for the summer season (1st of June to 31st of August).

The calculation of ACTI consists of three steps including data preparation (i.e. calculation of randomly weighted weather-type indices), data selection (i.e. identification of weather-types with strongest statistical relationships with the site chronologies) and ACTI calculation including the estimation of weather-type weights. The steps are summarized in the following.

In the first step, 1 million random number sets with 13 normally distributed random numbers, for each of the 13 summertime weather types, are used together with the weather-type frequency $\left(h_{\mathrm{yj}}\right)$ to compute weather-type indices. Consequently, 1 million weather-type indices are calculated using the Monte Carlo simulation.

The second step includes the selection of the suitable weather-type indices using a five-stage selection procedure:

1. From the calibration period $1881-1980,60$ discontinuous years were randomly selected in each Monte Carlo run. This was done to avoid overfitting of the model and to identify significant statistical relationships
(Pearson correlation coefficients) between the weathertype indices and the 78 TRW chronologies.

2. A multiple comparison adjustment (Carvajal-Rodriguez et al. 2009) is applied to reduce the observational errors.

3. For the selected weather-type indices, the Spearman rank correlation coefficients were calculated to reduce the influence of outliers. "Poor" performing (in our case $p>0.05$ ) weather-type indices and associated random number sets were excluded.

4. For the remaining weather-type indices and associated random number sets, only the best performing (30\% with the lowest $p$ value) random number sets for each chronology are considered for further analysis.

5. According to the law of large numbers the quality of the estimation of the weather-type weights $\left(g_{j}\right)$ increases with the number of random number sets. Therefore, at least 500 random number sets are required to reasonably determine the weights for each chronology. The selected Monte-Carlo simulations (in our case 500) that fit all criteria were averaged to a representative weather-type weight and used in Eq. 1. Due to the procedure, weather types that had a small influ- 
ence on tree growth will receive a weight value that approached or reached zero which has consequently no or a weak influence on the ACTI time series (Table 1).

In the third step, we focused on the detection of large-scale influences, so we used the strict five-stage selection procedure as described above. Thus, in our TRW network, 25 of the 78 site chronologies passed all selection criteria and the respective ACTI records were calculated for the common period 1871-1993. Finally, those were standardized (mean of zero and variance of one) and sign-adjusted, so that each ACTI record represents growth variations with positive/negative ACTI values denoting favorable/unfavorable growing conditions of the trees. For the final grouping, i.e. the identification of the common variability among all 25 ACTI records, we used a principal component analysis (PCA) (Peters et al. 1981). This process differed slightly from the procedure described by Schultz and Neuwirth (2012): as recently proven, the PCA approach is better to capture common large-scale climate signals than the grouping algorithm implemented in the original ACTI procedure (Schultz et al. 2015).

For the PCA, we chose the un-rotated solution instead of the varimax factor rotation method. However, both methods revealed similar results. PC scores were generated for the ACTI dataset. The contribution of each ACTI record on the PCs was defined by the loadings with a lower cutoff at \pm 0.45 (fair contribution) to ease the interpretation, and a stricter cut-off at \pm 0.63 (very good, Comrey and Lee 1992). The signs of the loadings indicated if tree growth at individual sites was negatively or positively influenced by the weighted impact of all 13 weather types (see Fig. S2). For example, trees from different locations can show opposite or weaker growth responses to the same weather type, which is reflected by the weather-type weights (Table 1) and ACTI records that include the weather-type frequencies. This is highlighted for two larch sites, where one positively (drought sensitive site mong013: loading of 1) and one negatively (temperature sensitive site russ 140: loading of 0.98) loaded onto ACTI-PC1. The two TRW site chronologies were significantly negatively correlated with each other $(r=-0.32 ; p<0.01)$, which is reflected in the negative associations between the corresponding ACTI records $(r=-0.97 ; p<0.001)$ for the period 1901-1993.

\subsection{Spatiotemporal characteristics of the detected circulation patterns}

Spatial correlations of the weather-type signals and associated climate parameters in the ACTI network were generated with $0.5^{\circ}$ by $0.5^{\circ}$ resolved grid point data across the larger Eurasian region using the KNMI climate explorer (http://climexp.knmi.nl/; Van Oldenborgh and Burgers
2005). All data were high-pass filtered using the year-toyear difference to maximize the response by removing trends in the climate data.

Additionally, to determine how well the ACTI is able to capture atmospheric circulation variability and to detect possible changes in the weather-type sensitivity of the tree ring chronologies as was found by Schultz et al. (2015), two different spatiotemporal analyses were conducted. First, the spatiotemporal dynamics of the dominant summertime ACTI patterns were investigated by generating 92 maps of 31-year running correlations covering the period 1871-1993. The video animations are provided as supplementary material (supplementary video $\mathrm{S} 1$ to $\mathrm{S} 3$ ).

Secondly, to investigate the temporal stability of the growth-weather type responses, smaller regions $\left(6^{\circ} \times 6^{\circ}\right.$ latitude by longitude grid) showing the strongest statistical relationships between ACTI (PC1 to PC3), SLP, and surface temperature were used. For each region, a time series of spatially averaged SLP was developed from the twentieth century reanalysis dataset. Finally, each averaged SLP time series was correlated with the ACTI components using 31-year running windows.

\section{Results}

\subsection{Tree-ring network characteristics}

The newly compiled TRW network included 56 drought and 22 temperature sensitive chronologies, respectively (Tab. S1). Trees responding to summer drought were equally distributed across the $80^{\circ}$ to $130^{\circ} \mathrm{E}$ longitudes, and were found at altitudes ranging from 500 to $2700 \mathrm{~m}$ asl with a mean elevation of $1531 \mathrm{~m}$ asl (Fig. 1). Lengths of the chronology after truncation varied from 141 (fir, Khonin Nuga, MN) to 569 (larch, Khorgo Lava, MN) years and a mean segment length of 326 years (Fig. 2; Tab. S1). Species being limited in growth by moisture conditions included one fir, 23 larch, 10 spruce and 22 pine sites. Growth rates were on average $0.9 \mathrm{~mm} /$ year and ranged from slow $(0.38 \mathrm{~mm} /$ year $)$ grown spruce trees at Kodarpass (Baikal, RU) to fast $(2.32 \mathrm{~mm} /$ year) grown pine trees at Honghuaerji (CN) (Fig. 2b; Tab. S1).

The temperature sensitive sites were located in the west of the study area, covering elevations from 1450 to $2840 \mathrm{~m}$ asl with an average of $2283 \mathrm{~m}$ asl (Fig. 1). Chronologies with a replication of 10 and more series covered a minimum of 174 years (spruce, Xinjiaing, $\mathrm{CN}$ ), a maximum of 1100 years (pine, Solongotyn Davaa, MN) and a mean segment length of 391 years (Fig. 2; Tab. S1). The compilation included two pine, five spruce and 15 larch sites. The average growth rates corresponded to the one calculated for the drought sensitive assemblage with $0.9 \mathrm{~mm} /$ year but ranged 

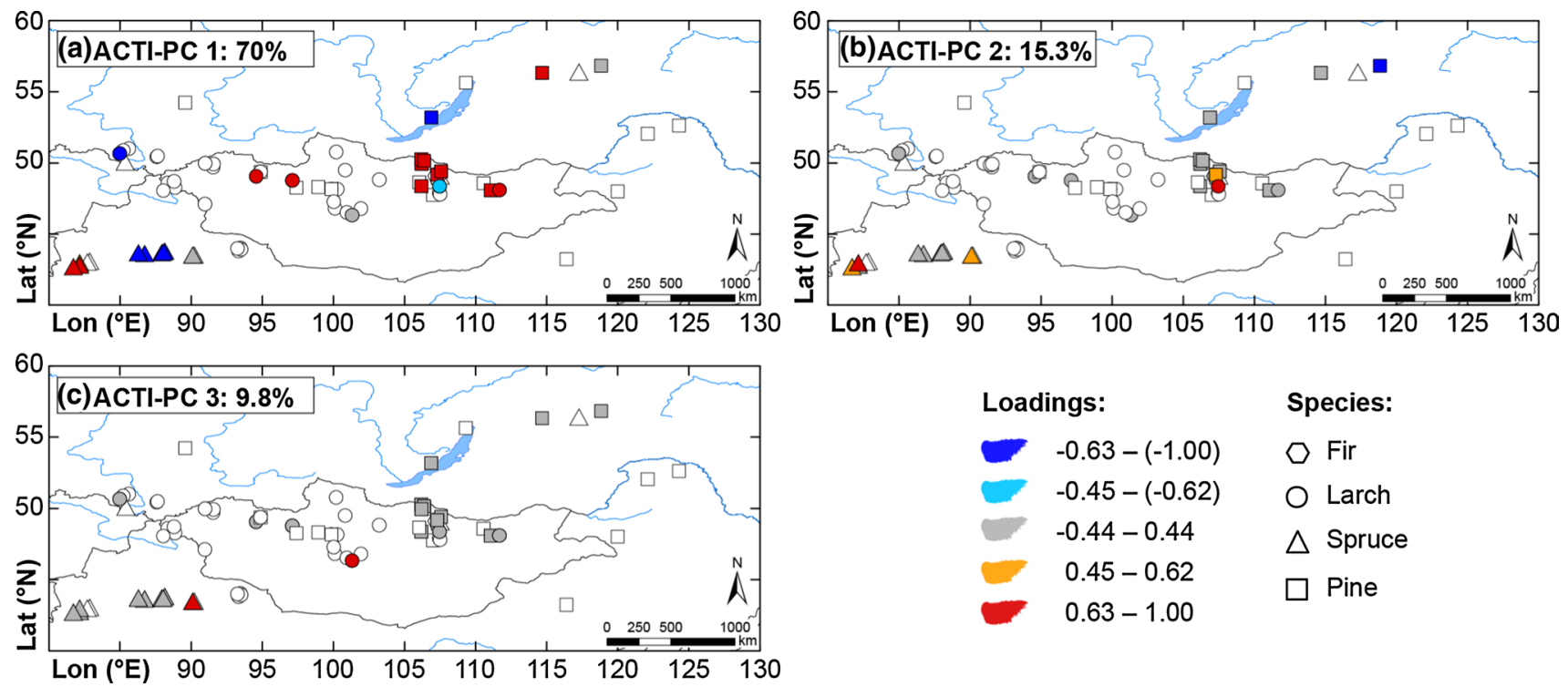

Fig. 5 Spatial distribution of the three PC's for the ACTI network (see legend for the sign of the loadings and species). Blank symbols indicate sites where the contribution of each ACTI record on the PCs was below the lower cut-off at \pm 0.45

from $0.37 \mathrm{~mm} /$ year (larch, Biarum Uul, MN) to only $1.56 \mathrm{~mm} /$ year (spruce, Xinjiaing, CN) (Fig. 2b; Tab. S1).

\subsection{Weather types and their frequency distribution}

Out of the 27 weather types, only 13 occurred during summer and the spatial patterns are displayed in Fig. 3 and Figure S3. The most frequent weather type was type 17 which occurred on average 20 days per summer, followed by type 3 ( $\sim 19$ days), type 23 ( $\sim 17$ days), type 21 ( $\sim 14$ days), type 8 ( $\sim 9$ days), and type 11 ( $\sim$ days) (Fig. 3 ). A common feature of these weather types was a low pressure system (indicated by low geopotential heights) of varying intensity and spatial extent over northwestern China (i.e. Tien Shan Mountains) including parts of southern Mongolia. However, this feature was associated with accompanying high and low pressure centers of varying intensity and location. Thus, resulting type-specific synoptic configurations lead to varying prevailing wind directions over the target region between North and Southeast (Fig. 3). The remaining weather types occurred much less frequently with fewer than three days (or 3.1\%) on average during the summer season (Fig. S3).

In Table 1 , the weight $\left(g_{j}\right)$ of each weather type on the 25 ACTI records is listed. It can be seen that weather type 3,21 and 23 contributed most to tree-growth variability in the study region. The average annual occurrence of each weather type during summer is displayed in Fig. 4. The variation of the frequencies showed that the six main weather types exhibited a high year-to-year variability as well as notable long-term changes. A significant decreasing trend was observed for weather type $23(r=-0.35$, $p<0.001)$, while type 21 experienced a significant $(r=0.33, p<0.001)$ increase in frequency over the 19011993 period.

\subsection{Characteristics of the ACTI patterns}

PCA results for the 25 newly generated ACTI records revealed that $95 \%$ of the networks' variance was exclusively explained by only three PC's (all three had eigenvalues greater than 1.0). Thus, three dominant atmospheric circulation patterns were extracted from the TRW data. ACTI-PC1 represented 70\%, ACTI-PC2 15.3\% and ACTI-PC3 $9.8 \%$ of the variance explained by the ACTI series belonging to this network, and the first two components were composed of negative and positive loaded variables (mixed sites) (Figs. 5, 6). The first factor, ACTI-PC1, explained most of the variance, being the leading pattern for 22 out of the 25 sites covering the entire study area at an average altitude of $1551 \mathrm{~m}$ asl (Fig. 5a). The majority of the sites showed drought responses (17 sites), and larch (five), pine (eight) and spruce (nine sites) were almost equally represented.

Sites assigned to ACTI-PC2 spread diagonally from northwestern China to southeastern Russia (Fig. 5b). ACTI-PC2 represented six sites, four temperature and two drought sensitive sites from two larch, one pine, and three spruce stands from elevations at $\sim 1800 \mathrm{~m}$ asl. ACTI-PC3 comprised two sites (larch and spruce) located in northwestern China and central Mongolia (Fig. 5c), which showed different climate responses, and were sampled at higher elevations ( 2400 m asl). 
Fig. 6 PC scores of the three ACTI components $(\mathbf{a}-\mathbf{c})$ highlighted for the period 1901-1993

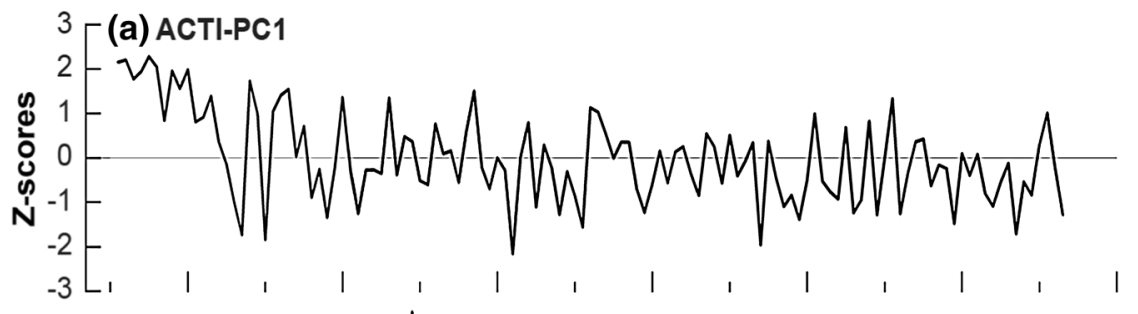

(b) ACTI-PC2
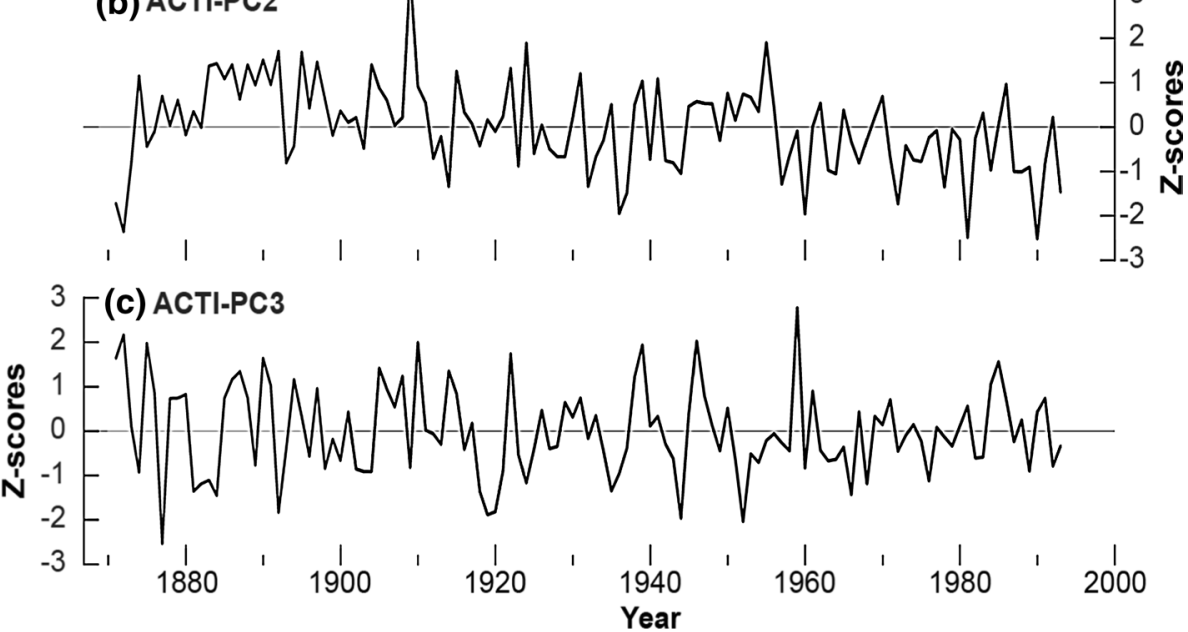

\subsection{Large-scale atmospheric circulation patterns and tree growth}

To describe the ACTI patterns, spatial correlations were calculated between each of the three ACTI components and a set of climate variables (SLP, 500-hPa fields, surface air temperature, precipitation and wind stress) for June-August over the period 1901-1993 (Fig. 7). It should be noted that even stronger statistical relationships were obtained for the period 1950-1993 (Fig. S4 a, c and e), when most climate data were available.

By definition of the ACTI procedure, the ACTI and TRW records are always positively correlated with each other and hence, the relationship with climate variables can be interpreted in two ways. For instance, is the ACTI negatively correlated with geopotential height, negative geopotential height anomalies can cause beneficial growth conditions or positive geopotential height anomalies can cause detrimental growth conditions for the trees (Fig. S2).

In our case, TRW chronologies with the strongest loadings in ACTI-PC1 responded to SLP anomalies over large parts of northern Eurasia with a center located over northern Russia (Fig. 7a). Favorable growth conditions at the mostly drought sensitive sites, thus positive ACTI values were associated with below-normal SLP anomalies over northern Russia and a weak high pressure system over northeastern China (Fig. 7a). Since winds are directed counterclockwise around a cyclone, this situation would correspond to cold-dry air masses propagating from the
Arctic region on the west side of the cyclone into mid-latitude Asia. At the eastern side of the cyclone, air masses from the South are transported northwards. Due to convection, at upper levels, a high pressure cell is developed over the study region with a branch extending into northeastern Russia (Fig. 7d). Under such conditions, positive correlations with surface temperatures are found (Fig. $7 \mathrm{~g}$ ). At the border between warm and cold air masses, precipitation occurs (Fig. 7j). This described pressure system and associated wind direction concurs with spatial correlations found for meridional wind stress at the surface (Fig. $7 \mathrm{~m}$ ). Since ACTI-PC1 includes predominantly drought sensitive trees, growth-limiting conditions are consequently associated with positive geopotential height anomalies over northern Russia (corresponding to negative ACTI values). The atmospheric circulation pattern found for ACTI-PC1 and its influence on tree growth is most pronounced for positive and negative extreme growth years (Fig. 8).

The circulation pattern determined for ACTI-PC2 was similar to the one for ACTI-PC1. However, the center of negative correlations with SLP was shifted towards northwestern Russia (Fig. 7b). At the same time, the low pressure system was less intense while a pronounced high pressure cell was visible over eastern Eurasia; a less pronounced feature for ACTI-PC1. At upper levels, both pressure systems were slightly shifted westwards with the anticyclone located west of Lake Baikal (Figs. 7e, 8). Thus, high temperatures favor tree growth in the Altay and Tien Shan Mountains in the west and northwest, while a precipitation 

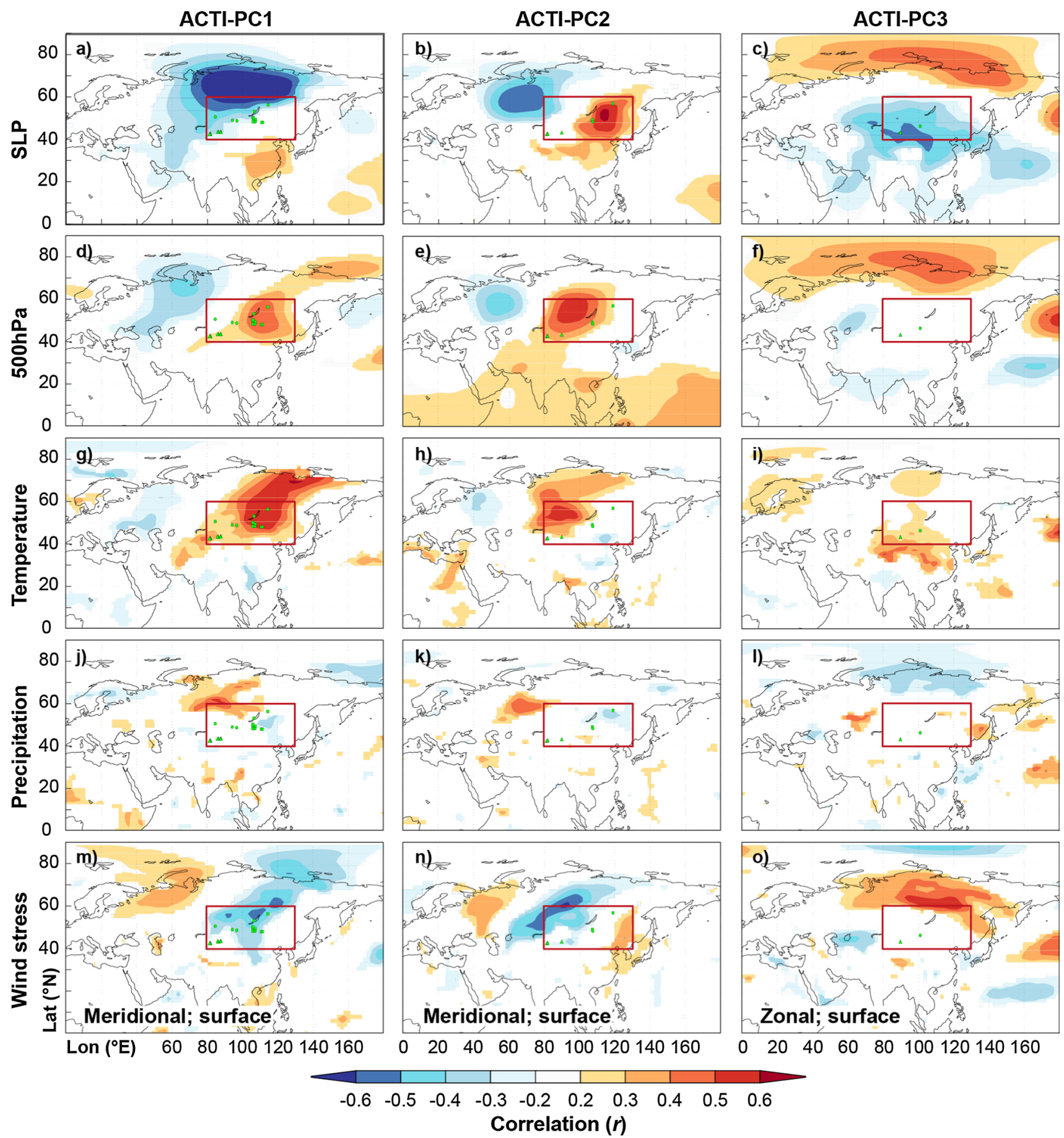

Fig. 7 Spatial correlations of the three ACTI components (from left to right: ACTI-PC1 to ACTI-PC3) and June-August sea level pressure (SLP), $500 \mathrm{hPa}$ geopotential height, surface air temperature, pre-

deficit was indicated, though weak, in the northeast of the study area (Fig. 7h, k). Low wind flow coincided with the center of the high pressure system (Fig. 7n), leading to dry and sunny weather conditions over western Mongolia and northern Russia. In this case, the weather conditions were cipitation and wind stress (with specification in the panels) from the twentieth century reanalysis dataset for the period 1901-1993. Red squares show the study domain and green symbols the TRW sites

favorable for growth of the temperature sensitive trees at high elevation sites.

ACTI-PC3 showed a zonal circulation pattern across Eurasia (Fig. 7c). Positive correlations were found with SLP and at upper levels over northern Russia and the East 

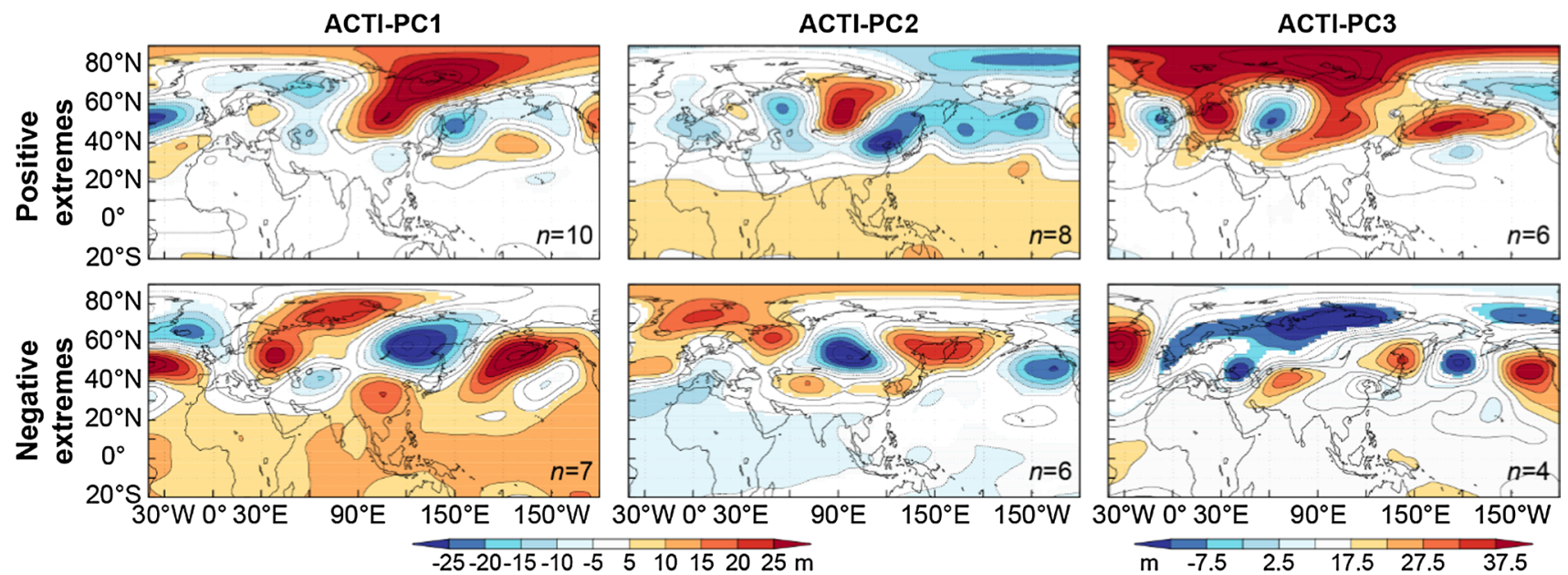

Fig. 8 Composite maps of June-August $200 \mathrm{hPa}$ geopotential height anomaly fields for positive (upper panel) and negative (lower panel) ACTI years $(n)$ that exceeds \pm 1.5 standard deviation for the period

Siberian Sea, while a belt of negative SLP anomalies was located across the mid-latitudes with maximum negative correlations southwest of Lake Baikal (Figs. 7c, f, 8). Thus, cyclonic weather conditions in the study region were beneficial for tree growth at the two sites. Although correlations with precipitation were insignificant over the period 19011993 (Fig. 7l), an increase in zonal wind flow (Fig. 7o) can be associated with warm (Fig. 7i) and moist air arriving in the region.

\section{Discussion}

\subsection{Data and statistical analyses}

Our study region stretches over more than $5500 \mathrm{~km}$ in an east-west and $2200 \mathrm{~km}$ in a north-south direction across mid-latitude Asia. Topography is diverse including several mountain ranges such as the Tien Shan and the Altai in the west and the Gobi desert in southern Mongolia and north/northwestern China (Fig. 1). This high diversity in terrain and the lack of a dense network of long meteorological station data challenges dendroclimatological studies, and limit the understanding of surface climate variability in this region. To ensure consistency of the results, the twentieth century reanalysis dataset was chosen for the calculation of the ACTI and for the investigation of spatiotemporal information of the weather-type responses from the ACTI components. Despite the existence of other shorter reanalysis products, this dataset is ideal to capture the high atmospheric variability in the mid-latitudes and consequently, the higher variability in the weathertype frequencies. This is best considered in the ACTI
1901-1993. ACTI records were high-pass filtered using a 10-year spline. Shadings are significant at the $90 \%$ significance level. Please note changes in legend for negative extreme years of ACTI-PC3

procedure by a calibration period of more than 90 years. The twentieth century reanalysis dataset also incorporates uncertainty estimates and long climate records are available back to 1871 . However, inhomogenities have been found in the early parts of the records for the northeast Atlantic sector (Krueger et al. 2013), most likely due to the low amount of instrumental data prior 1950 (Compo et al. 2011). Therefore, we cannot fully exclude inconsistencies in the results from the early part of the analyzed period. Moreover, this can be also one of the reasons for the temporally changing correlation patterns between ACTI and SLP (see Fig. 9 and supplementary video S1 to $\mathrm{S} 3$ ).

We calculated a new ACTI for each TRW chronology, which explains more comprehensively the climate signals obtained from TRW chronologies and more importantly, the interaction between different climate parameters (Schultz and Neuwirth 2012). This was done using an objective weather classification scheme for the warm season based on the twentieth century reanalysis data (Fig. S1). Although the COST733 software was developed for Europe, successful applications for other regions were conducted as for instance for the investigation of precipitation variability for the Tibetan Plateau (Liu et al. 2016).

We used the $95 \%$ significance level to include sites with strong weather-type responses, which resulted in 25 relevant ACTI records. Although this number may seem very low compared to the input dataset of 78 sites, a change in threshold allows less summer weather-type sensitive sites to enter the analysis and consequently, may weaken the final results. To avoid this, we aimed for a high signal-tonoise ratio to extract the main atmospheric circulation patterns from tree rings in this region. 

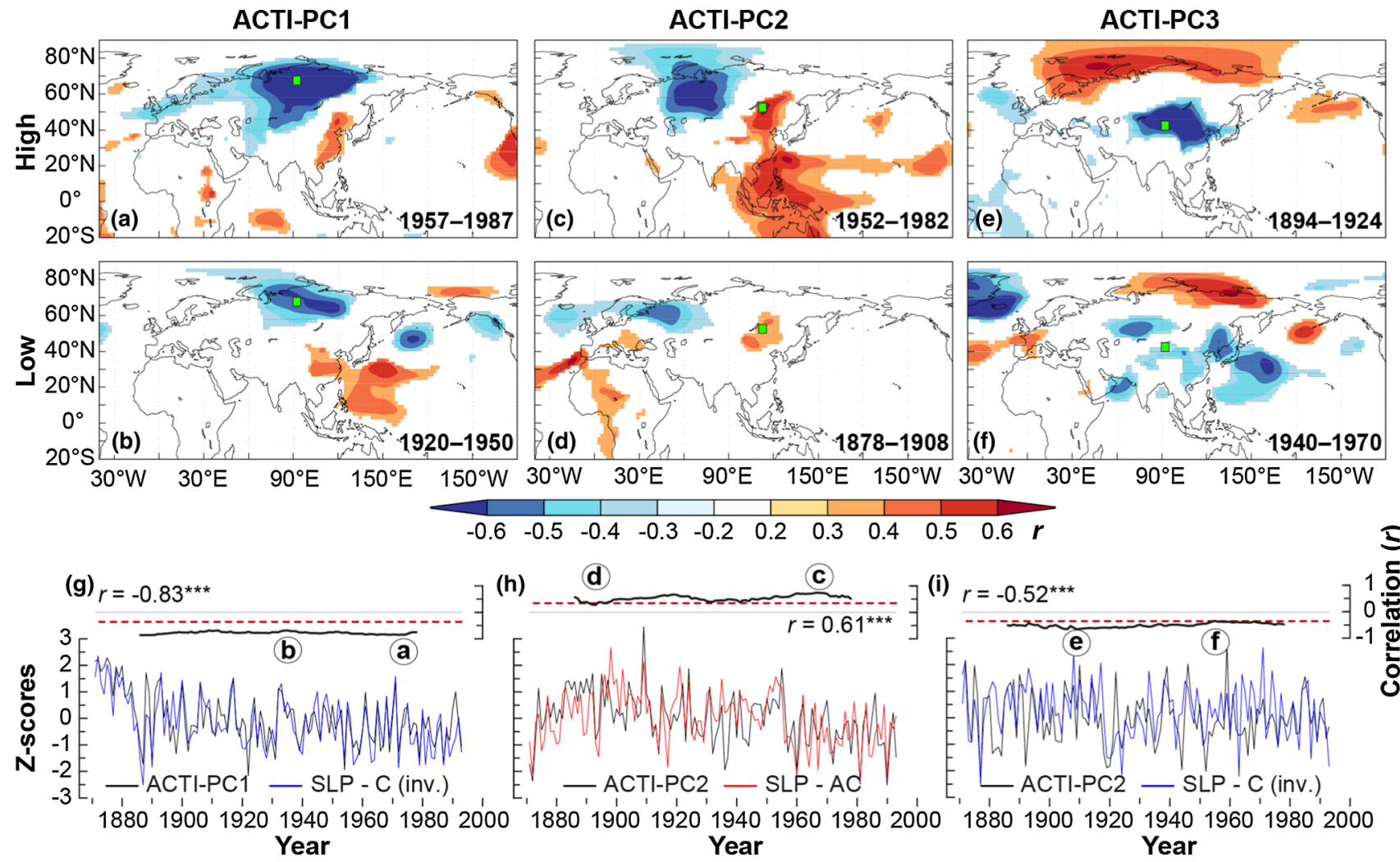

Fig. 9 Spatial correlation maps $(\mathbf{a}-\mathbf{f})$ of the temporal relationship $(\mathbf{g}-\mathbf{i})$ between the three ACTI components and sea level pressure [SLP; averaged for a smaller region (green squares)] anomalies with high (upper panel) and low correlation (lower panel) for a 31-year period. Negative/positive SLP anomalies correspond to cyclonic

\subsection{ACTI components and corresponding TRW data}

Each of the obtained ACTI components (PC's) showed specific biogeographic signatures. The first component (ACTI-PC1) mainly included drought sensitive trees from lower elevations and ACTI-PC2 was composed of primarily temperature sensitive TRW data from higher elevations, while ACTI-PC3 comprised only two chronologies from very high elevations. In this context, it is interesting that contrary to regional patterns generally obtained from TRW networks, the sites for the ACTI components cluster in less geographically confined patterns. For ACTI-PC1 a rather widespread coverage was obtained while ACTI-PC2 showed a diagonally, southwest-northeast oriented pattern across the entire study region (Fig. 5). Likely, the ACTI cluster follows distinct boundaries of atmospheric pressure systems. However, this fact makes the ACTI cluster less comparable with results obtained from regionalization approaches based on TRW networks in this region (e.g. Leland et al. 2013).

To test if the TRW chronologies with the strongest contribution to the three ACTI components indeed exhibit
(C)/anticyclonic (AC) conditions in panel $(\mathbf{g - i})$, where a 31-year running correlation was applied (black line). The 95\% significance level is indicated by a red dashed line. Pearson correlation values provided are obtained for the full period 1871-1993 (three asterisks indicate significance at the $99.9 \%$ level)

the same weather-type responses, we correlated the corresponding composite (i.e. averaged group) TRW chronologies with SLP for a shorter period 1950-1993 (Fig. S4). Generally, the TRW data showed similar correlation patterns with SLP as obtained for the ACTI components. However, correlation values were overall weaker and synoptic-scale circulation patterns were less distinctively defined. This can be related to a higher noise-to-signal ratio in the TRW data, whereas the ACTI records represent the extracted weather-type signals. This is the case for ACTIPC1, for instance, where the corresponding TRW composite chronology does not depict the strong negative SLP anomalies over northern Russia (Fig. S4a and b).

\subsection{Synoptic-scale circulation dynamics}

Our study region, located between the $40^{\circ} \mathrm{N}$ and $60^{\circ} \mathrm{N}$ parallel, generally lies within the extratropical zone where upper-level westerly winds dominate. During summer, three major zones of cyclonic activity influence the study region: the Asiatic Arctic Front extending in an east-west direction across northwestern Siberia along the $70^{\circ} \mathrm{N}$ latitude, the 
Asian Polar Front extending from Central Asia (i.e. Kazakhstan) over Mongolia to northeastern China along the $50^{\circ} \mathrm{N}$ latitude causing anticyclonic cells between $50^{\circ} \mathrm{N}$ and $55^{\circ} \mathrm{N}$, and the South Asian Intertropical Front (Dando 2005). The latter reaches the $25^{\circ} \mathrm{N}$ parallel in China during summer (Fig. 1) and merges with the already developed deep Southwest Asian low-pressure cell over Pakistan and northeastern India. Between those fronts, the Polar Front jet (following often a meandering course) and the Subtropical jet stream are developed, although the latter slowly weakens in May, disintegrates in June, and causes the westerlies to flow north into central Asia. At the surface, however, winds flow from north/northeastern Russia to Central Asia, Pakistan and northeastern India, i.e. into the Southwest Asian low (Barry and Carleton 2001 and references therein).

The eastward propagation of the upper-troposphere westerlies from the East Atlantic towards Asia is important for climate and thus, tree growth in mid-latitude Asia (Fig. 7, $500 \mathrm{hPa}$ geopotential height anomalies). This association is more pronounced using $200 \mathrm{hPa}$ geopotential height fields (Fig. 8), where positive and negative extreme growth years for all three ACTI components are shown. Thus, local climate is modulated by a wave train like pattern in the upper troposphere linking the North Atlantic and Eurasia in summer. This cross-Eurasian teleconnection pattern, the summer circumglobal wave train, modulates precipitation and surface air temperature in western Europe, Eurasia, India, east Asia and North America (Ding and Wang 2005; Saeed et al. 2014; Zhu et al. 2011). Ding and Wang (2005) also found a strong link with the Indian summer monsoon and El Niño Southern Oscillation. Saeed et al. (2014) used precipitation data from Europe and identified an opposite response for the summer NAO than for the circumglobal wave train. Our results show both the north-south dipole like pressure patterns of the summer NAO (Folland et al. 2009) for ACTI-PC1 and negative extreme years for ACTI-PC2 (Fig. 8), and an east-west dipole like pattern of the circumglobal wave train (Saeed et al. 2014) for positive extreme years for ACTI-PC2 and ACTI-PC3 (Fig. 8).

On regional scale, our results are in accordance with Chen and $\mathrm{Lu}$ (2014), who found the same teleconnection pattern after analyzing surface air temperature for the summer season for the northeastern China region, and the leading pattern obtained by Chen et al. (2016) highly corresponds to the ACTI-PC1 pattern (Fig. 7). Chen and Lu (2014) argued that strong southwesterly winds in the west of the locally developed positive $500 \mathrm{hPa}$ geopotential height anomaly prevent cold air to flow from the high latitudes to northeastern China, resulting in higher than normal temperatures.

Additionally, the influence of the Intertropical Convergence Zone was associated with negative extreme growth anomalies in ACTI-PC1 and positive extreme growth anomalies for ACTI-PC2 (Fig. 8). Ding and Wang (2007) investigated the intra-seasonal teleconnection between the Indian summer monsoon and the summer wave train, and discovered a recurrent coupling pattern between the two. Huang and Wu (1989) found that during El Niño conditions, i.e. anomalous warm sea surface temperatures of the equatorial Pacific Ocean, low rainfall amounts occur in northern and southern China.

\subsection{Spatiotemporal character of the synoptic-scale circulation patterns}

The identified atmospheric circulation patterns showed spatiotemporal variability, as can be seen in the supplementary video S1 to S3. By extracting SLP data for a smaller region at the center of the pressure anomalies (Fig. 9; green squares), we found that ACTI-PC1 showed a stable association with negative geopotential height anomalies over northern Russia and strongest negative correlations were obtained for the period 1957-1987 (Fig. 9a and g). Contrary, the lowest correlation was between 1920 and 1950, although still significant at the $95 \%$ significance level (Fig. 9b, g). Temporal variations in the association between ACTI-PC2 and the center of positive geopotential height anomalies southeast of Lake Baikal, showed highest positive correlations in the early and late twentieth century (Fig. 9c, i). For ACTI-PC3, a weakening in the negative relationship with low SLP anomalies was observed around 1950 with low, but significant $(p<0.05)$ correlations for 1940-1970 (Fig. 9f, j). The weakening of the low pressure belt across mid-latitude Asia coincides with the negative (positive) winter (summer) NAO phase observed during the early 1940's to early 1970's (Portis et al. 2001 and references therein). At the same time, stronger positive associations with the anticyclonic system across eastern Asia can be seen for ACTI-PC1 (Fig. 9b) and ACTI-PC2 (Fig. 9c). The NAO is associated with large-scale changes in the intensity and location of the North Atlantic jet stream and storm tracks, changes in the zonal and meridional moisture and heat transport are accompanied during winter and summer (Hurrell 1995; Linderholm et al. 2011). Thus, changes in the circulation pattern can be linked to variations in the dominant climate modes across the Northern Hemisphere.

\section{Conclusion}

Based on a well-replicated dataset of 78 TRW chronologies and the application of the recently developed ACTI procedure, we were able to extract significant tree growth relevant weather types and furthermore, to determine related major synoptic-scale circulation patterns during summer 
for mid-latitude Asia. Thus, we can extend the period normally used in climatological studies in this region over the full twentieth century.

We found three major atmospheric circulation patterns reflecting the climatic influence on tree growth at sites with distinct biogeographic characteristics. The first PC represented sites with drought sensitive trees, where growth benefited from negative geopotential height anomalies low pressure anomalies developed over northern Russia. Tree growth of primarily temperature sensitive trees at mid-elevation sites was enhanced when anticyclonic climate conditions over Mongolia and northeastern Eurasia prevailed. Two sites sampled at high altitudes showed links to air masses originating from the Pacific.

For the first time, we successfully linked summer weather conditions and tree rings, both in space and time, to evaluate atmospheric circulation patterns extracted from groups of similarly responding tree-ring sites in mid-latitude Asia, where atmospheric action centers are largely absent. Hence, our findings do not only contribute to the understanding of synoptic-scale climate variability in a region that is threatened by drastic climate changes. Moreover, we provide a basis where large-scale synoptic processes can be reconstructed from tree-ring networks or used in climate model simulations for Asia.

Acknowledgements We are grateful to all authors who made their tree-ring data available through the Tree-Ring Data Bank. This work was funded by the Swedish International Development Cooperation Agency SIDA (Project SWE-2009-245) and partially by Adlerbertska forskningsstiftelsen. This research contributes to the strategic research areas Modelling the Regional and Global Earth system (MERGE), and Biodiversity and Ecosystem services in a Changing Climate (BECC). This is contribution no. 35 from the Sino-Swedish Centre for Tree-Ring Research (SISTRR). H. W. Linderholm was supported by Swedish Research Council (VR, Grant 2012-5246) and E. Liang was supported by National Natural Science Foundation of China (41525001).

Open Access This article is distributed under the terms of the Creative Commons Attribution 4.0 International License (http://creativecommons.org/licenses/by/4.0/), which permits unrestricted use, distribution, and reproduction in any medium, provided you give appropriate credit to the original author(s) and the source, provide a link to the Creative Commons license, and indicate if changes were made.

\section{References}

Barry RG, Carleton AM (2001) Synoptic and dynamic climatology. Routledge Publishing, London

Beck C, Philipp A (2010) Evaluation and comparison of circulation type classifications for the European domain. Phys Chem Earth, Parts A/B/C 35(9):374-387

Böhner J (2006) General climatic controls and topoclimatic variations in Central and High Asia. Boreas 35:279-295
Carvajal-Rodriguez A, de Una-Alvarez J, Rolan-Alvarez EA (2009) A new multitest correction (SGoF) that increases its statistical power when increasing the number of tests. BMC Bioinform 10:209

Chen W, Lu R (2014) The interannual variation in monthly temperature over Northeast China during summer. Adv Atmos Sci 31(3):515-524

Chen F, Yu Z, Yang M, Ito E, Wang S, Madsen DB, Huang X, Zhao Y, Sato T, Birks HJB (2008) Holocene moisture evolution in arid central Asia and its out-of-phase relationship with Asian monsoon history. Quat Sci Rev 27:351-364

Chen Z, Zhang X, He X, Davi NK, Cui M, Peng J (2013) Extension of summer (June-August) temperature records for northern Inner Mongolia (1715-2008), China using tree rings. Quat Int 283:21-29

Chen W, Hong X, Lu R, Jin A, Jin S, Nam J-C, Shin J-H, Goo T-Y, Kim B-J (2016) Variation in summer surface air temperature over northeast asia and its associated circulation anomalies. Adv Atmos Sci 33(1):1-9

Compo GP et al (2011) The twentieth century reanalysis project. Q J Roy Meteorol Soc 137:1-28

Comrey AL, Lee HB (1992) A first course in factor analysis, 2nd edn. Lawrence Erlbaum Associates, Hillsdale

Cook ER (1985) A time series analysis approach to tree rings standardization. Ph.D. dissertation, University of Arizona

Cook ER, Krusic PJ (2005) Program ARSTAN: a tree-ring standardization program based on detrending and autoregressive time series modeling, with interactive graphics. Lamont-Doherty Earth Observatory, Columbia University, Palisades, NY

Cook ER, Peters K (1997) Calculating unbiased tree-ring indices for the study of climatic and environmental change. Holocene 7:361-370

Cook ER, Anchukaitis KJ, Buckley BM, D'Arrigo RD, Jacoby GC, Wright WE (2010) Asian monsoon failure and megadrought during the last millennium. Science 328:486-489

Dando WA (2005) Asia, climates of Siberia, Central and East Asia. In: Oliver JE (ed) Encyclopedia of world climatology. Springer, Berlin, pp 102-114

D’Arrigo R, Jacoby G, Pederson N, Frank D, Buckley B, Nachin B, Mijiddorj R, Dugarjav C (2000) Mongolian tree-rings, temperature sensitivity and reconstructions of Northern Hemisphere temperature. Holocene 10:669-672

D'Arrigo RD, Jacoby G, Frank D, Pederson N, Cook ER, Buckley BM, Nachin B, Mijiddorj R, Dugarjav C (2001) 1738 years of Mongolian temperature variability inferred from a treering width chronology of Siberian pine. Geophys Res Lett 28:543-546

Davi N, Jacoby G, Curtis A, Baatarbileg N (2006) Extension of drought records for central Asia using tree rings: west-Central Mongolia. J Clim 19:288-299

Davi N, Jacoby G, D’Arrigo R, Baatarbileg N, Jinbao L, Curtis A (2009) A tree-ring-based drought index reconstruction for farwestern Mongolia: 1565-2004. Int J Climatol 29:1508-1514

Davi NK, D’Arrigo R, Jacoby GC, Cook ER, Anchukaitis K, Nachin B, Rao MP, Leland C (2015) A long-term context (931-2005 CE) for rapid warming over Central Asia. Quat Sci Rev 121:89-97

Ding H (2004) Seasonal march of the East-Asian summer monsoon. In: Chang C-P (ed) East Asian Monsoon. World Scientific, Singapore, pp 3-53

Ding Q, Wang B (2005) Circumglobal teleconnection in the northern hemisphere summer. J Clim 18(17):3483-3505

Ding Q, Wang B (2007) Intraseasonal teleconnection between the summer Eurasian wave train and the Indian Monsoon. J Clim 20(15):3751-3767 
Enke W, Spekat A (1997) Downscaling climate model outputs into local and regional weather elements by classification and regression. Clim Res 8:195-207

Fang K, Gou X, Chen F, Zhang F, Li Y, Peng J (2010) Comparisons of drought variability between central High Asia and monsoonal Asia: inferred from tree rings. Front Earth Sci-China 4:277-288

Fang K, Gou X, Chen F, Liu C, Davi N, Li J, Zhao Z, Li Y (2012) Tree-ring based reconstruction of drought variability (16152009) in the Kongtong Mountain area, northern China. Glob Planet Change 80:190-197

Folland CK, Knight J, Linderholm HW, Fereday D, Ineson S, Hurrell JW (2009) The summer North Atlantic Oscillation: past, present, and future. J Clim 22:1082-1103

Fritts HC (1976) Tree rings and climate. Academic, New York

Gong DY, Ho CH (2003) Arctic oscillation signals in the East Asian summer monsoon. J Geophys Res-Atmos (1984-2012) 108(D2):4066

Hartigan JA (1975) Clustering algorithms. Wiley, New York

Holmes RL (1983) Computer-assisted quality control in tree-ring dating and measurement. Tree-Ring Bull 43:69-78

Huang RH, Wu Y-F (1989) The influence of ENSO on the summer climate change in China and its mechanism. Adv Atmos Sci 6:21-32

Hurrell JW (1995) Decadal trends in the North Atlantic Oscillation: regional temperatures and precipitation. Science 269(5224):676-679

IPCC (2013) Climate change 2013: the physical science basis-contribution of working group I to the fifth assessment report of the intergovernmental panel on climate change. Cambridge University Press, New York

Jacoby GC, D'Arrigo RD, Davaajamts T (1996) Mongolian tree rings and 20th-century warming. Science 273:771-773

Krueger O, Schenk F, Feser F, Weisse R (2013) Inconsistencies between long-term trends in storminess derived from the $20 \mathrm{CR}$ reanalysis and observations. J Clim 26:868-874

Leland C, Pederson N, Hessl A, Nachin B, Davi N, D'Arrigo R, Jacoby G (2013) A hydroclimatic regionalization of central Mongolia as inferred from tree rings. Dendrochronologia 31:205-215

Li J, Yu R, Zhou T (2008) Teleconnection between NAO and climate downstream of the Tibetan Plateau. J Clim 21:4680-4690

Liang E, Leuschner C, Dulamsuren C, Wagner B, Hauck M (2016) Global warming-related tree growth decline and mortality on the north-eastern Tibetan plateau. Clim Change 134(1):163-176

Linderholm HW, Ou T, Jeong J-H, Folland CK, Gong D, Liu H, Liu Y, Chen D (2011) Interannual teleconnections between the summer North Atlantic Oscillation and the East Asian summer monsoon. J Geophys Res-Atmos (1984-2012) 116(D13):D13107

Liu H, Williams AP, Allen CD, Guo D, Wu X, Anenkhonov OA, Liang EY, Sandanov DV, Yin Y, Qi Z, Badmaeva NK (2013) Rapid warming accelerates tree growth decline in semi-arid forests of inner Asia. Glob Change Biol 19:2500-2510

Liu W, Wang L, Chen D, Tu K, Ruan C, Hu Z (2016) Large-scale circulation classification and its links to observed precipitation in the eastern and central Tibetan Plateau. Clim Dyn 46(11):3481-3497

Lu R (2005) Interannual variation of North China rainfall in rainy season and SSTs in the equatorial eastern Pacific. Chin Sci Bull 50:2069-2073

Pederson N, Jacoby GC, D'Arrigo RD, Cook ER, Buckley BM, Dugarjav C, Mijiddorj R (2001) Hydrometeorological reconstructions for Northeastern Mongolia derived from tree rings: 1651-1995. J Clim 14:872-881

Pederson N, Hessl AE, Baatarbileg N, Anchukaitis KJ, Di Cosmo N (2014) Pluvials, droughts, the Mongol Empire, and modern Mongolia. Proc Natl Acad Sci USA 111(12):4375-4379

Perry A (1971) Changes in position and intensity of major northern hemisphere 'centres of action'. Weather 26:268-270

Peters K, Jacoby GC, Cook ER (1981) Principal components analysis of tree-ring sites. Tree-Ring Bull 41:2-19

Philipp A et al (2010) Cost733cat: a database of weather and circulation type classifications. Phys Chem Earth, Parts A/B/C 35(9):360-373

Philipp A, Beck C, Huth R, Jacobeit J (2014) Development and comparison of circulation type classifications using the COST 733 dataset and software. Int J Climatol. doi:10.1002/joc.3920

Portis DH, Walsh JE, Hamly ME, Lamb P (2001) Seasonality of the North Atlantic oscillation. J Clim 14:2069-2078

Rao MP, Davi NK, D'Arrigo RD, Skees J, Nachin B, Leland C, Lyon B, Wang S-Y, Byambasuren O (2015) Dzuds, droughts, and livestock mortality in Mongolia. Environ Res Lett 10(7):074012

Saeed S, Van Lipzig N, Müller WA, Saeed F, Zanchettin D (2014) Influence of the circumglobal wave-train on European summer precipitation. Clim Dyn 43(1-2):503-515

Sahsamanoglou H, Makrogiannis T, Kallimopoulos P (1991) Some aspects of the basic characteristics of the Siberian anticyclone. Int J Climatol 11:827-839

Schultz JA, Neuwirth B (2012) A new atmospheric circulation treering index (ACTI) derived from climate proxies: procedure, results and applications. Agr For Meteorol 164:149-160

Schultz JA, Beck C, Menz G, Neuwirth B, Ohlwein C, Philipp A (2015) Sensitivity of proxies on non-linear interactions in the climate system. Sci Rep 5:18560

Sun J, Wang H (2012) Changes of the connection between the summer North Atlantic oscillation and the East Asian summer rainfall. J Geophys Res-Atmos (1984-2012) 117:D08110

Vaganov EA, Hughes MK, Shashkin AV (2006) Growth dynamics of conifer tree rings: images of past and future environments. Springer, Berlin

Van Oldenborgh GJ, Burgers G (2005) Searching for decadal variations in ENSO precipitation teleconnections. Geophys Res Lett 32(15):L15701

Wang B (2006) The Asian monsoon. Springer, Berlin

Wang B, Wu R, Fu X (2000) Pacific-East Asian teleconnection: how does ENSO affect East Asian climate? J Clim 13:1517-1536

Wang X, Brown PM, Zhang Y, Song L (2011) Imprint of the Atlantic multidecadal oscillation on tree-ring widths in Northeastern Asia since 1568. PLoS ONE 6(7):e22740. doi:10.1371/journal. pone. 0022740

Wigley TML, Briffa KR, Jones PD (1984) On the average value of correlated time series, with applications in dendroclimatology and hydrometeorology. J Clim Appl Meteorol 23:201-213

Zhang R, Sumi A, Kimoto M (1999) A diagnostic study of the impact of El Nino on the precipitation in China. Adv Atmos Sci $16: 229-241$

Zhu X, Bothe O, Fraedrich K (2011) Summer atmospheric bridging between Europe and East Asia: influences on drought and wetness on the Tibetan Plateau. Quat Int 236:151-157 